\title{
A AUTONOMIA E A DEMOCRACIA NA UNIVERSIDADE E SEUS DILEMAS
}

AUTONOMY AND DEMOCRACY IN THE UNIVERSITY AND ITS DILEMMAS

Wrana Maria Panizzi

Universidade Federal do Rio Grande do Sul, RS, Brasil E-mail:wrana@terra.com.br

Recebido em: 12.11.2018 - Aceito em: 17.01.2019

DOI: http://dx.doi.org/10.5902/2526629235593

\section{INTRODUÇÃO}

A universidade, uma vez mais, está em discussão e, com ela, a sua autonomia e a sua democracia, temas estes de permanente debate e reflexão já faz algum tempo em vários fóruns e instâncias dentro e fora da universidade, tanto no âmbito nacional quanto internacional. Essas questões - que têm como pedra de toque a autonomia e a democracia - são tidas como condição fundamental para que essa instituição de educação superior cumpra o seu papel de agente de transformação social, econômica e cultural de um país, de uma nação. Tal movimento acontece, nesse momento, no contexto de uma chamada internacional, liderada pela Unesco - que, neste ano, celebra os 100 anos da Reforma de Córdoba, ocorrida em 1918, reforma essa tida como um marco histórico na trajetória da universidade latino-americana e caribenha. Daí a realização da III Conferência Regional de Educação Superior - CRES 2018 -, realizada na Universidade de Córdoba (Argentina), em junho de 2018 (ver a declaração da CRES 2018).

Motivada por esse evento, o presente texto busca chamar a atenção para algumas ideias que têm como mote a importância e o significado dessa questão presente e fundamental para a vida universitária, qual seja, a da sua legitimidade como instituição dotada de incidência social e a da compreensão da natureza e essência desses conceitos para se pensar a própria universidade, a sua manutenção e a sua longevidade como instituição secular voltada para o ensino, a pesquisa e a extensão.

O tema é antigo e dele todos querem falar, desde professores, técnicos administrativos, estudantes, até outros tantos setores da sociedade, tais como governos, sindicatos, organizações empresariais, organismos internacionais e regionais. Isso, sem dúvida, deve-se ao amplo reconhecimento de que a informação, o conhecimento e, em termos mais amplos e fundacionais, a educação assumiram na contemporaneidade, de forma robusta, a classificação de "bem" que agrega valor e promove o crescimento e o desenvolvimento da sociedade. 
Não há necessidade de muito esforço e revisão do que já foi dito e escrito sobre autonomia e democracia nas universidades para se constatar que quase tudo o que se escreveu até agora sobre o tema sempre esteve atrelado aos aspectos jurídicos e institucionais que envolvem a questão da autonomia "das" e "nas" universidades brasileiras. Quando falo "das universidades", refiro-me a estas como instituições autônomas em relação ao Estado, enquanto a referência ao "nas universidades" diz respeito à escolha de seus dirigentes e reitores, que, ainda hoje, passam pela chancela do Estado a partir de uma lista tríplice, o que implica certa ingerência do segundo sobre as primeiras.

Além disso, há também, entre essa vasta gama de estudos e escritos, uma certa repetição que pouco ou nada avança em função da redundância dos argumentos, que, de certa forma, coloca em evidência um certo conformismo que me desafia a pensar a questão da autonomia universitária e da democracia na universidade desde uma outra perspectiva, de um outro lugar - que escapa dos ditames do direito e das discussões jurídicas que envolvem a instituição em si -, e a coloca no interior do sistema político colapsado e em crise há mais de vinte anos, como já escrevi em outro lugar (Panizzi, 2018). Trata-se de um lugar que, desde o campo da filosofia, leva-me a pensar essa crise há tanto tempo anunciada por Boaventura de Sousa Santos (1997) e que depois de vinte anos ainda se mantém, a partir de uma relação dialética - e quase doentia, que beira o onírico e o quimérico - de uma universidade que se quer livre e autônoma, mas que depende do Estado para se manter.

A partir dessa anunciada crise institucional, entre nós, aqui no Brasil, esse lugar tem sua pedra de toque na discussão da necessidade ou não de a universidade mudar o seu estatuto jurídico institucional - se é autarquia, se é fundação etc. Também passa pelo questionar-se acerca do seu lugar e espaço no contexto da administração pública do Estado brasileiro. Como promover a organização administrativa da universidade e ao mesmo tempo manter-se onde está? Nesse sentido, como pensar o seu financiamento, pensar a universidade e os recursos nela investidos, mas que também envolve uma prestação de contas desta: mas para quem? Como? E por quê? E se esta optar por do jugo do Estado se livrar?

Contudo, penso que o cerne da questão não está aí nem nessa série de questionamentos que até aqui arrolei. Este se localiza, sim, no interesse em conhecer as concepções, os conceitos que se referem à universidade e ao seu papel, os quais antecedem a discussão que envolve a forma de autonomia e os instrumentos de ação que determinam o que as universidades podem ou não fazer, e sob que vigilância! 
Assim, a reflexão é mais profunda, diria mesmo que ela é filosófica. Por quê? Porque a autonomia é mais um valor intrínseco à universidade do que um arcabouço a determinar a sua atuação e o seu protagonismo, embora seja a mesma a autonomia - necessária e imprescindível para que a universidade cumpra o seu papel, mas que também é indissociável da ideia de democracia na universidade.

\section{OS 20 ANOS DE CRISE NA UNIVERSIDADE E UM MESMO DESAFIO A SUPERAR?}

Em meados da década de 1990, Boaventura de Sousa Santos publicou um texto sobre a universidade, suas crises e desafios, que ecoou de forma gutural em diversos circuitos acadêmicos e não acadêmicos, mas que logo caiu no esquecimento. Tal texto intitulava-se "Da ideia de universidade à universidade de ideias" e compunha uma de suas obras mais ácidas e provocativas - a saber: "Pela mão de Alice: o social e o político na pós-modernidade" -, antes do jocoso "Epistemologia do Sul". Nesse texto, o referido sociólogo português identificava as três crises com as quais a universidade se defrontava e se debatia naqueles tempos, quais sejam: 1) a crise da hegemonia; 2) a crise da legitimidade; e 3) a crise institucional.

A primeira, chamada de "a crise da hegemonia" - como ele mesmo aponta -, era resultado das contradições existentes entre as funções tradicionais da universidade e aquelas que, ao longo do século XX, foram the sendo atribuídas, como muito bem registra Chauí (2003). Como escreve Sousa Santos (2011, p. 8), se por um lado a universidade tinha como função "a produção de alta cultura, pensamento crítico e conhecimentos exemplares, científicos e humanísticos, necessários à formação das elites que a universidade se tinha vindo a ocupar desde a idade média europeia", por outro, ela também tinha que - dada as exigências que lhe eram impostas - ocupar-se com "a produção de padrões culturais médios e de conhecimento instrumentais, úteis na formação de mão de obra qualificada [esta] exigida pelo desenvolvimento capitalista".

Com o decorrer dos anos, a universidade foi se mostrando incapaz de lidar com isso, de modo que, aos poucos, tanto o Estado quanto os agentes econômicos que a financiavam foram levados a procurar fora da universidade meios alternativos que lhes permitissem atingir seus objetivos. A partir desse momento, vemos proliferar os cursos técnicos e sequenciais, bem como os chamados MBAs, que, ao voltarem-se para o atendimento das necessidades do mercado e do Estado, acabavam por colocar a universidade de lado, fazendo com que esta, 
ao deixar de ser a única instituição que detinha o domínio do ensino superior e da pesquisa, entrasse em uma crise de hegemonia e passasse, assim, a ter que concorrer com outros atores, que, a partir desse momento, passam a jogar o jogo (Bourdieu, 2003).

Desta primeira crise, deriva a segunda, qual seja, a chamada "crise da legitimidade", provocada pelo fato de a universidade ter deixado de ser uma instituição que sozinha detinha o monopólio do ensino superior e do saber especializado, na medida em que há, com a instauração da primeira crise, uma contradição:

Entre a hierarquização dos saberes especializados através das restrições de acesso e da credenciação das competências, por um lado, e as exigências sociais e políticas da democratização da universidade e a reivindicação da igualdade de oportunidades para os filhos das classes populares, por outro (Sousa Santos, 2011, p. 9).

A terceira, denominada de "crise institucional, deriva, como já discutimos em outro momento (Panizzi \& Meirelles, 2014), de um certo conjunto de contradições existentes no interior da universidade, que resulta da contradição "entre a reivindicação da autonomia na definição dos valores e objetos da universidade e a pressão crescente de submeter esta última a critérios de eficácia e produtividade ou de responsabilidade social", como muito bem registra Sousa Santos (2011, p. 9).

Contudo, tais crises nunca foram solvidas, sendo apenas geridas no interior da universidade, de modo a se evitar o seu aprofundamento. Seu instrumento para isso baseava-se na sua longa e secular memória institucional, que, apesar de eivada de ambiguidades administrativas, buscava reagir às pressões do momento. Sobretudo, como observa Sousa Santos (2011, p. 9), "tratava-se de uma atuação ao sabor das pressões (reativa), com incorporação acrítica de lógicas sociais e institucionais exteriores (dependentes) e sem perspectivas de médio e longo prazo (imediatista)".

$\mathrm{E}$, agora, passados mais de vinte anos desse sonoro e gutural grito de socorro da universidade, que "pela mão de Alice", pediu-nos ajuda, o que mudou? Nada.

A crise institucional que apontamos no início deste texto tornou-se o foco das atenções e monopolizou, no Brasil, praticamente todas as ações ligadas à universidade e às políticas a ela relacionadas, tanto no âmbito das propostas mais conservadoras - de se manter a representatividade docente, discente e técnico-administrativa na proporção de 70/15/15 em todos os órgãos colegiados e representativos da maioria das Instituições de Ensino Superior (IES), por exemplo - quanto reformistas - ligadas à criação do Programa Universidade para Todos (ProUni), do Programa de Apoio a Planos de Reestruturação e Expansão das Universidades Federais (Reuni), 
das novas universidades e dos institutos federais etc.

Dessa feita, tal movimento, do ponto de vista estratégico, implicou uma ilusão sistêmica - e canhestra - de que as crises da hegemonia e da legitimidade da universidade estariam solvidas, o que, de fato, não ocorreu. Contudo, em função da crescente descaracterização intelectual da universidade, aprofundou-se ainda mais a crise da hegemonia, na medida em que essa inseriu novos atores que passam, também, a disputar o monopólio da formação de especialistas em diferentes áreas do conhecimento e que a esteira do exposto anteriormente levou a uma crescente segmentação e hiperespecialização do sistema universitário.

Esse movimento trouxe consigo uma pujante desvalorização dos diplomas universitários e uma enlouquecida corrida à pós-graduação, que, já faz alguns anos, mostra dar sinais de esgotamento em função das métricas e critérios utilizados para sua avaliação, os quais quase nunca levam em conta as especificidades de cada área. Apesar desse cenário desolador, mudanças ainda são possíveis.

Todavia, para que isso aconteça, é preciso que se pense em um projeto de universidade que possa ser sustentado por um certo conjunto de forças e atores sociais disponíveis e interessados em protagonizá-lo, sem, contudo, a universidade em si deixar de ser a principal protagonista e promotora de sua autonomia -e não o contrário, como vemos hoje, em que a universidade muito mais serve aos interesses do Estado do que aos seus próprios. Desse modo, como escreve Sousa Santos (2011, p. 59), a universidade deixa de ser, hoje, "um campo social muito fraturado e que em seu seio digladiam-se setores e interesses contraditórios".

É preciso, como já nos apontaram os contratualistas clássicos, que pensemos a universidade como um locus privilegiado da democracia, onde deve imperar a liberdade de pensamento, a igualdade de condições e de decisão em seu interior, sem esquecer, todavia, seu fim último - formar cidadãos e profissionais aptos a pensar e repensar a sociedade em prol do bem comum e do desenvolvimento de condições que permitam à humanidade avançar em direção ao futuro.

Mas isso não deve ser uma decisão a ser tomada de cima para baixo. É preciso que a universidade se sinta e seja juridicamente autônoma - pois será somente assim que esta se livrará das amarras daquele que a mantêm sob seu jugo. $\mathrm{Na}$ alegoria de Hegel, somente continua escravo quem se coloca como tal em relação ao seu senhor e com ele antagoniza, sem nunca deste senhor se ver liberto. 


\section{AUTONOMIA UNIVERSITÁRIA E CONTROLE ESTATAL À LUZ DA DIALÉTI- CA HEGELIANA}

A célebre relação dialética entre o senhor e o escravo tem sido, desde muito tempo, alvo de muitas discussões e apropriações, tanto no campo da filosofia quanto das ciências humanas de uma maneira mais geral. Tal qual aquilo que caracteriza um texto clássico, este tem sido muitas vezes revisitado e repensado como um modo de compreensão da realidade que toma como dada a existência de uma relação antagônica entre dois polos/categorias diversas. Contudo, desde que Marx resolveu se ocupar desse excerto da obra de Hegel para pensar o modo como a sociedade evoluiu ao longo dos tempos - através de sua inversão e da construção de uma dialética da positivação, como já escreveram em outro lugar Meirelles e Pedde (2014) -, essa discussão se tornou uma das maiores encruziIhadas com a qual o pensamento pós-hegeliano tem se ocupado.

Mas como não é nosso foco discutir aqui o método dialético e como ele tem sido empregado/usado pelos mais diversos pensadores das ciências sociais como uma forma de interpretar a realidade, buscamos nas próximas páginas nos servir da dialética da negação proposta por Hegel como mote para pensar o dilema que envolve a relação entre Estado e Autonomia Universitária, a partir de certos condicionantes legais e históricos que envolvem o modo como o sistema universitário público está organizado no Brasil. Isso porque este segue um caminho bastante diverso daquele pelo qual enveredou toda a América Espanhola, seja por seu caráter tardio, seja em função de determinadas especificidades ligadas à metrópole portuguesa de outrora.

No entanto, o tema do senhorio e da servidão com o qual se ocupa Hegel ao pensar a relação entre o senhor e o escravo escapa em muito das reduções hermenêuticas do marxismo e do pós-marxismo, na medida em que, diferentemente do que se pensa e de como a maioria dos pós-hegelianos lê a obra de Hegel, esta não se restringe a um momento e/ou a um contexto histórico específico. O que importa é o modo como essa relação de existência/negação é construída entre dois elementos antagônicos que só existem porque colocados em relação, mas que, fora da relação, deixam de existir como entidades singulares independentes. Em função disso, temos que:

A dialética do Senhor e do Escravo assinala a emergência, na textura de um discurso de extrema tecnicidade, de um desses veios profundos da filosofia não escrita que correm ao longo da cultura ocidental. Eles assinalam a continuidade de certas experiências fundadoras que sustentam e orientam o relevo de determinado solo cultural. A dialética do Senhor e do Escravo aflora na superfície do texto de Hegel a partir desse veio muito profundo ou dessa experiência fundadora que 
configura as sociedades ocidentais desde a sua aurora grega como sociedades políticas, ou seja, sociedades constituídas em torno da luta pelo reconhecimento, oscilando entre os polos da physis que impele a particularidade do interesse e do desejo, e do nomos que rege a universalidade do consenso em torno do bem reconhecido e aceito. (Lima Vaz, 1981, p. 7-8).

Nesse sentido, a partir do exposto por Durham (2006), podemos dizer que a ideia de autonomia universitária está muito mais ligada a uma ideia de valor e à existência de um certo nomos reconhecido e aceito que impele a um desejo e interesse manifesto que se articula mais à noção de physis do que a um preceito legal que, por força de lei, outorga certa parcela de poder e decisão - derivada do fantasmagórico Leviatã de Hobbes (2004) - às instituições universitárias, impelindo-as a ocupar-se de suas questões, de sua gestão no seio de um modelo de Estado cada vez mais nominalista. Este é preconizado pela agenda liberal desde o século passado e, com o neoliberalismo, viu-se revitalizado nas últimas décadas através de um conjunto de leis e reformas que, cada vez mais, têm alterado a natureza e o modo como o Estado tem se colocado em relação à sociedade.

Se, por um lado, como escreve Lima Vaz (1981, p. 8), temos que, "para Hegel, a luta pelo reconhecimento, que inaugura o curso histórico das sociedades ocidentais, tem o seu desenlace, no nível do discurso ou da sua significação pensada", por outro, temos que pensar que a ideia de autonomia universitária e sua relação para com o poder constituído também envolvem a elaboração de todo um quadro de contingência a partir do qual tal noção pode ser pensada em termos absolutos (autonomia absoluta), relativos (autonomia relativa) e situacionais (autonomia situacional). Esse movimento envolve o entendimento a priori dessa relação antagônica que existe entre a universidade que se quer livre e autônoma e o Estado que a tem sob sua tutela e jugo.

Estamos, portanto, falando de uma universidade que se quer autônoma e que para isso necessita do Estado para financiá-la, mas também de um Estado que financia essa universidade que se faz autônoma, mas que, dado o modo como o sistema superior de ensino federal está organizado, tem-na sob seu controle, escolhendo, por exemplo, a partir de uma lista tríplice aquele que será o seu reitor. É aí que reside o grande dilema que envolve a ideia de autonomia universitária, qual seja, de como a universidade pode, ao mesmo tempo que nega a existência daquele que a financia - o Estado -, não deixar de existir, como é caso da relação que existe entre o senhor que só se reconhece senhor na medida em que tem o outro como escravo, ao mesmo tempo que o escravo somente se mantém como escravo porque reconhece e antagoniza com aquele que lhe torna cativo, o seu senhor. 


\section{ALGUMAS CONSIDERAÇÕES FINAIS, MAS PROVISÓRIAS}

Com vistas a fazer um fechamento do texto e de uma questão deveras inconclusa, retomamos aqui os preceitos e princípios da Reforma de Córdoba (1918), para, então, fora do âmbito das discussões mais comuns que tratam do tema, pensar aquilo que se deseja - em termos de autonomia para a universidade - e o que se avançou em termos práticos nesses quase cem anos que separam a reforma em si das reflexões e discussões que neste texto são apresentadas quando colocamos essa relação de subserviência entre o Estado e a universidade em xeque.

Comecemos dizendo que a autonomia universitária na América Latina e Caribe está intrinsecamente ligada ao movimento estudantil desencadeado no continente a partir do Manifesto de Córdoba de 21 de junho de 1918, na Argentina. Tal manifesto (1918) é tido, grosso modo, como o lugar mítico a que faz referência a maioria dos textos e resgates históricos que buscam delinear/construir/identificar as origens da ideia de autonomia e que, de certa forma, condiciona aquilo que hoje se pensa sobre esta no seio da maioria de nossas universidades públicas latino-americanas.

Entretanto, se observarmos as diferentes análises e reflexões sobre esse movimento, o que verificamos é que, embora a chamada Reforma de Córdoba tenha se constituído no referencial ideológico dos diferentes movimentos universitários autonomistas, esse manifesto não faz referência explícita à questão da autonomia nem às características e/ou o modo como a universidade deve relacionar-se com o Estado. O que ele faz é uma crítica severa à vida interior da universidade: ao seu anacronismo acadêmico, ao seu autoritarismo e à postura burocrática que muitas vezes, ainda hoje, encontra eco em nossas universidades.

Mas, se o movimento e a Reforma de Córdoba não citam explicitamente a autonomia, fica implícito neles o seu papel - a partir do seu caráter latino-americano e das propostas a ela ligadas, tanto por parte do Estado como por parte da universidade -, qual seja, de que a ideia de autonomia tem sido utilizada como um instrumento que serve a múltiplos usos: ora para o Estado deixar-se de fora de suas responsabilidades diante da universidade; ora para a universidade realizar mudanças em sua estrutura; ora para o Estado garantir e colocar em prática determinadas políticas e/ou fomentar determinados setores da sociedade; ora para a universidade dizer-se livre e autóctone e, assim, dar efetividade aos vínculos sociais que ela estabelece com diversos setores da sociedade.

Mas qual o significado da autonomia, por que se fala tanto dela e para que ela é desejada? Grosso modo, podemos dizer que a ideia de autonomia a que se refere o texto da lei a compara a uma moeda - e aqui me refiro à ideia de dinheiro mesmo, 
de uma moeda de troca - que ora tem lastro e ora não tem, de modo que seu valor é dado em função das negociações que se tem no campo e daquilo que, em um dado momento, a universidade e/ou Estado consideram importante valorizar.

A ideia de autonomia é, por assim dizer, quase um pacto, um contrato reconhecido, uma carta de alforria de um e de outro, embora ambos tenham medo de pedir a sua execução. O primeiro em função de que irá perder a sua principal aliada, seja para o bem, seja para o mal, a universidade. A segunda em função de que irá perder o seu mantenedor - o Estado - e de que terá de garantir, então, a sua manutenção e sustento. Desse modo, o que temos a partir da exegese do texto hegeliano é, por um lado, um Senhor que liberta seu escravo, mas que, sem ele para antagonizar, deixa de existir; e, por outro, um Escravo que se vê liberto, mas que sem seu senhor não vê possibilidades de sobreviver.

Dessa feita, temos, então, que a ideia de autonomia da universidade é formulada a partir da relação desta com o Estado. Assim sendo, podemos dizer que, de fato, a ideia de autonomia é sempre uma construção permanente a partir da qual a universidade, ao longo do tempo e em função dela, tem procurado no seu cotidiano legitimar-se, funcionando como o locus da sua efetiva legitimidade.

Contudo, algumas linhas já estão dadas e têm sua inspiração na ideia de autonomia proposta pela União das Universidades da América Latina e do Caribe (Udual), do país vizinho Uruguai, a qual propunha, ainda em 1953, uma autonomia cujo conceito passou a encontrar ao longo do tempo uma grande aceitação, segundo o qual:

La autonomia de la Universidad es el derecho desta Corporacion a dictar su propio régimen interno y a regular exclusivamente sobre él; es el poder de la Universidad de organizarse y de administrarse a sí mesma. Dicha autonomía es consustancial a su propia existencia y no a una merced que le sea otorgada - y debe ser asegurada como una de las garatías constitucionales. (La Reforma Universitaria, 1953, p. 32).

Assim, é fato que a luta pela autonomia atravessou todo o século $X X$, especialmente na sua busca de aceitação e respeito por parte dos organismos públicos e da sociedade em geral. E aqui uma vez mais recorremos às experiências de algumas importantes universidades latino-americanas a partir daquilo que ensinou a Universidade Nacional Autônoma do México (UNAM), quando pautou a sua ação em uma declaração do seu Conselho Universitário na qual se explica a maneira como a autonomia universitária se integra com as três autonomias inseparáveis: acadêmica, administrativa e legislativa. Conforme asseverou em 1966: 
Autonomía universitaria es esencialmente la libertad de enseñar, investigar y difundir la cultura. Esta autonomia académica no existe de un modo completo si la universidad no tuviera el derecho de organizarse, de funcionar y de aplicar sus recursos económicos como lo estime más conveniente, es decir, si no poysera una autonomia administrativa; y si no disfrutara de una autonomia legislativa, que es su capacidad para dictarse sus propios ordanamientos. (La Reforma Universitaria, 1966, p. 32).

Contudo, para instituir o seu autogoverno e suas próprias leis, a universidade tem passado por desafios e lutas que buscam, de fato, preservar e garantir a sua governabilidade autônoma - algo que, na maioria das vezes, encontra obstáculos que são interpostos por diferentes políticas, ações do poder público, muitas delas sustentadas por críticas e movimentos contestatórios gestados no seio da sociedade em geral e impostos a ela via organismos públicos e privados nacionais e internacionais, tais como o Banco Mundial, OCDE, Unesco etc.

Assim, se a luta pela autonomia tem marcado os longos anos de história da universidade, junto a ela está presente também o combate ao pensamento dominante, na expressão de que - pensamento único - dá sustentabilidade ao predomínio dos ideais dos países metropolitanos sobre a formação e a educação do conjunto das nações. Dessa forma, se a autonomia é uma possibilidade que permite e garante a construção de uma universidade livre, também é necessária ainda para outros fins, que envolvem a luta contra a privatização das universidades, a desnacionalização dessas instituições e sua usurpação, bem como o combate à transformação destas em empresas mercantilistas.

Hoje, sem dúvida, essas perspectivas assumem dimensões vitais e são cada vez mais difundidas e apoiadas em todos os países, desde suas grandes cidades e capitais até suas áreas mais profundas, onde o apoio à privatização das universidades e a consolidação do conceito de educação como uma mera mercadoria com valor de troca vêm se constituindo em moeda forte. A autonomia é, pois, também um instrumento de luta externa, junto à sociedade internacional, para a defesa de um estado social onde a universidade seja autônoma, laica, qualificada e gratuita, ou, melhor dizendo, um agente de transformação social.

Contudo, o tom de tais reflexões e constatações - do meu ponto de vista - não encerra a discussão, mas deixa abertas algumas janelas que nos permitem pensar os principais pontos que orientaram a Reforma de Córdoba - e que acredito importantes -, a serem retomados e pensados a partir de três eixos: o da autonomia (que autonomia temos para isso e que autonomia queremos?), o da instituição em si (que universidade temos e que universidade queremos?) e o da democracia (de que modo participamos das decisões no interior da universidade hoje e de que modo queremos participar no futuro?). 


\section{REFERÊNCIAS}

Bernheim, C. T. (1996). Breve historia del desarrollo de universidad em América Latina: El fenomeno de la temprana fundacion de universidades em el nuevo mundo. In La educacion superior en el umbral del siglo XXI. Caracas: CRESALC. p. 11-38.

Bourdieu, P. (2003). O poder simbólico. Rio de Janeiro: Bertrand Brasil.

Chauí, M. (2003). A universidade pública sob nova perspectiva. In Revista Brasileira de Educação, 24, p. 5-15.

Durham, E. R. (2006). A autonomia universitária: extensão e limites. In Steiner, J. E., \& Malnic, G. (orgs.). Ensino Superior: Conceito e dinâmica. São Paulo: EDUSP.

Hobbes, T. (2004). Leviatã: Ou, matéria, forma e poder de um estado eclesiástico e civil. São Paulo: Martin Claret.

Lima Vaz, H. C. (1981). Senhor e Escravo: uma parábola da filosofia ocidental. Síntese, 8(21), p. 7-29.

Panizzi, W., Meirelles, M. (2014). Em busca das origens: pensando o papel da universidade e seus compromissos com o desenvolvimento local e do país. In Colóquio Internacional de Gestão Universitária - GIGU, Anais... Florianópolis: INPEAU, 15, p. 1-20.

Sousa Santos, B. (1997). Pela mão de Alice: O social e o político na pós-modernidade. São Paulo: Cortez.

Sousa Santos, B. (2011). A universidade no século XXI: Para uma reforma democrática e emancipatória da universidade. São Paulo: Cortez.

III Conferência Regional de Educação Superior para a América Latina e o Caribe. (2018). Declaração. Córdoba, Argentina. 